\title{
Neuropathic Pain Questionnaire and Neuropathic Pain Questionnaire-Short Form: Translation, Reliability, and Validation Study of the Turkish Version
}

\author{
Ozan Volkan YURDAKUL ${ }^{1}$, Aylin REZVANI², Okan KUCUKAKKAS ${ }^{1}$, Sena TOLU², Mehmet Serkan KILICOGLU1, \\ Teoman AYDIN ${ }^{1}$
}

${ }^{1}$ Bezmialem Vakıf University, Faculty of Medicine, Department of Physical Medicine and Rehabilitation, Istanbul, Turkey

${ }^{2}$ Medipol University, Faculty of Medicine, Department of Physical Medicine and Rehabilitation, Istanbul, Turkey

Corresponding author: Ozan Volkan YURDAKUL yurdakul_ozan@yahoo.com

\section{ABSTRACT}

AIM: To perform reliability and validity studies of the Neuropathic Pain Questionnaire (NPQ) and NPQ-Short Form (SF) in the Turkish language.

MATERIAL and METHODS: The Turkish translation and cross-cultural validation were performed. Then, 101 patients (36 males, 65 females; mean age: $50.4 \pm 14.49$; range: $20-87$ ) with chronic pain were asked to fill out a pack of questionnaires, including the NPQ, NPQ-SF, Douleur Neuropathique 4 (DN4), Leeds Assessment of Neuropathic Symptoms (LANSS), and Numeric Rating Scale (NRS). A subgroup of 41 patients (11 males, 30 females) completed the NPQ and NPQ-SF for the second time after 3 days by telephone. Internal consistency was tested by Cronbach's- $a$ and test-retest reliability was assessed by calculating the intraclass correlation coefficients (ICC). Construct validity was assessed by comparing NPQ, NPQ-SF, and NRS. Concurrent validity was tested by comparing NPQ, NPQ-SF, DN4, and LANSS.

RESULTS: Internal consistency by Cronbach's-a was 0.84 and 0.67 for the NPQ and NPQ-SF, respectively, indicating adequate and low internal consistency, respectively. ICC was $0.96(p<0.001 ; 95 \%$ confidence interval $[C l], 0.95-0.97)$ for NPQ and 0.97 ( $p<0.001$; 95\% Cl, 0.95-0.97) for NPQ-SF, indicating a high test-retest reliability for both questionnaires.

CONCLUSION: The Turkish versions of NPQ and NPQ-SF were reliable and valid for patients with chronic pain. To our knowledge, this is the first Turkish adaptation and test of the reliability and validity of the NPQ and NPQ-SF (short-form). These questionnaires could potentially help clinicians who seek to assess neuropathic pain for clinical and investigational purposes.

KEYWORDS: Neuropathic pain questionnaire, Cross-cultural adaptation, NPQ, Reliability, Validity

ABBREVIATIONS: MRI: Magnetic resonance imaging, NeuPSIG: The neuropathic pain special interest group, IASP: Internal association for the study of pain, DN4: Douleur neuropathique 4, LANSS: Leeds assessment of neuropathic symptoms, NPQ: Neuropathic pain questionnaire, NPQ-SF: Neuropathic pain questionnaire - short form, NRS: Numerical rating scale, ICC: Intraclass correlation coefficient, Cl: Confidence interval.

Ozan Volkan YURDAKUL (10: :0000-0003-4567-8133 Aylin REZVANI Okan KUCUKAKKAS
(D) : 0000-0002-5852-3854

(1) : 0000-0001-6971-4229
Sena TOLU

(1) : $0000-0002-1111-3110$

Mehmet Serkan KILICOGLU (1) : 0000-0001-6303-5735

Teoman AYDIN
(D) : 0000-0002-0902-6771 


\section{INTRODUCTION}

$\mathrm{N}$ europathic pain is defined as pain arising from a lesion or disease affecting the somatosensory system (22). Therefore, neuropathic pain includes highly heterogeneous and difficult-to-treat clinical conditions associated with a large variety of central and peripheral nervous lesions (7). Consensus is growing that a significant proportion of common pain consists of combined nociceptive and neuropathic pain (15). Neuropathic pain in chronic pain patients varies between $3 \%$ and $17 \%$ in the general population (24).

Rapid and correct diagnosis of neuropathic pain is clinically important because it is necessary to start appropriate treatment in a timely manner (22). Full examination and testing for neuropathic pain (electromyography, magnetic resonance imaging [MRI], and so forth) can be time-consuming; therefore, questionnaires for practical assessment of neuropathic pain have been developed $(6,12)$. The Neuropathic Pain Special Interest Group (NeuPSIG) of the Internal Association for the Study of Pain (IASP) recommended five questionnaires for screening neuropathic pain (12): Douleur Neuropathique 4 (DN4) (7), ID pain (20), Leeds Assessment of Neuropathic Symptoms (LANSS) (5), pain DETECT questionnaire (10), and the Neuropathic Pain Questionnaire (NPQ) (17). Although up to $20 \%$ of neuropathic pain cases are not identified by these questionnaires and such questionnaires cannot be used to replace clinical diagnosis, they are used widely for standard assessment of symptoms in clinical practice and clinical trials (9).

To the best of our knowledge, NPQ and its shortened form (NPQ-SF) was never translated and validated in Turkish. We translated and culturally adapted these questionnaires into Turkish and tested their reliability and validity in patients with chronic pain.

\section{MATERIAL and METHODS}

\section{Participants}

This observational study included 101 chronic pain patients who met the eligibility criteria for participation in this study, including age $\geq 18$ and suffering chronic pain ( $\geq 3$ months). The exclusion criteria were inability to consent, having acute or subacute pain, and inability to speak fluent Turkish.

All the participants were recruited from the outpatient clinic of the authors and provided written informed consent before participation. Ethical approval was obtained from the institutional ethical committee (No: 2018-4418). Permission was obtained from the developer of these questionnaires before the study.

\section{Translation and Cross-Cultural Adaptation}

Translation and cross-cultural adaptation was performed following the criteria suggested by Beaton et al. (4). In the first stage, two Turkish individuals, an informed (medical doctor) and an uninformed translator (no health professional background), translated the NPQ into Turkish. After obtaining initial forward translations, the translations were compared and reviewed by a bilingual individual who highlighted any conceptual errors or inconsistencies in the translations and established the first Turkish translation in a reconciliation meeting. Then, two native English translators, unaware of the purpose of the study and with no access to the original English version, performed backward translations. The backward translated versions were compared to the original questionnaire version by an expert committee (the four translators, a language expert, and experts from the research group) and the prefinal version of the Turkish questionnaire was produced. The preliminary testing of the prefinal version was conducted on 20 patients with chronic pain to determine the difficulties in understanding the questions. After the preliminary testing, "bunaltıcl (overpowering)" was used instead of "baskın (overwhelming)" in question 10 asking "how overwhelming is your usual pain?" for better understanding in the final version. The final Turkish version of these questionnaires was approved by the developer of the original questionnaires.

\section{Instruments}

The original NPQ consists of 12 selected questions of 32 (17). From these 12 questions, 10 query the quality of pain (burning pain, overly sensitive to touch, shooting pain, numbness, electric pain, tingling pain, squeezing pain, freezing pain, unpleasant pain, overwhelming pain), while two question sensitivity changes (increased pain due to touch, increased pain due to weather changes). The patients were asked to rate their usual pain in each question from 0 (none) to 100 (most). Then, calculation with the coefficients total discriminant function score was obtained. A total discriminant function score $<0$ indicated nonneuropathic pain, while a score $\geq 0$ indicated neuropathic pain. The NPQ was originally developed in the United States, with $74.7 \%$ sensitivity and $77.6 \%$ specificity (17). Chinese (18), Italian (19), and Swedish (14) versions also exist, but with less evidence than the original version (9).

The NPQ-SF was developed from a descriptive analysis of $12 \mathrm{NPQ}$ questions, three of which (tingling pain, numbness, increased pain due to touch) were considered to differentiate neuropathic from nonneuropathic pain (3). As with the original NPQ, patients were asked to rate their usual pain in each question from 0 (none) to 100 (the most imaginable). Total discriminant function scores $<0$ and $\geq 0$ indicated nonneuropathic and neuropathic pain, respectively. Sensitivity was $64.5 \%$ and specificity was $78.6 \%$ (3), and an Arabic version also exists (21).

The Numerical Rating Scale (NRS) (16) assesses the current overall pain intensity with 11 points, from 0 (no pain) to 10 (worst pain) and indicates how much general pain exists without differentiating the types of pain.

The LANSS is a seven-item pain scale consisting of a grouped sensory description and sensory examination with a simple scoring system (5). The first five questions ask about the presence of unpleasant skin sensations (pricking, tingling, pins, and needles), skin appearance (mottled, red, or pink), increased sensitivity to touch, sudden bursts of electric 
shock sensations, and hot or burning skin sensations. The last two questions query sensory testing for the presence of allodynia and altered pinprick threshold. Points relative to their significance are given for positive answers. A score $\geq 12$ indicates neuropathic pain, with $85 \%$ sensitivity and $80 \%$ specificity (5).

The DN4 is a simple 10-item questionnaire attempting to distinguish neuropathic from nonneuropathic pain, and consists of seven sensory descriptors (burning, painful cold, electric shocks, tingling, pins and needles, numbness, and itching) and three signs related to sensory examination (hypoesthesia to touch, hypoesthesia to prick, and pain increased by brushing) (7). A cutoff score with four positive symptoms achieved $82.9 \%$ sensitivity and $89.9 \%$ specificity (7).

The Turkish version of the NPQ was administered with NRS, LANSS, and DN4 questionnaires to 101 patients with chronic neuropathic and nonneuropathic pain. The Turkish translated and validated versions of LANSS and DN4 were used $(23,25)$. Patients completed the questionnaires for the first time in the clinic. A subgroup of 41 patients completed the NPQ questionnaire for the second time by telephone interview three days after the first completion for analysis of test-retest reliability. The NPQ contained the same three questions as the NPQ-SF. Therefore, instead of asking the same questions twice we used the relevant questions from the NPQ for NPQSF analyses.

\section{Statistical Analysis}

All the statistical analyses were achieved with IBM SPSS (Statistical Package for Social Sciences for Windows, Version 21.0; IBM Corp., Armonk, NY, USA) package software.
Quantitative variable behavior was defined using measures of centralization and variation (mean \pm SD). Statistical significance was established at $\mathrm{p}=0.05$ for all cases.

For internal consistency, Cronbach's-a coefficients were calculated. A Cronbach's-a of <0.6, 0.6-0.7, and 0.7-0.95 indicated poor, low but reasonable, and adequate internal consistency, respectively (11).

To determine test-retest reliability, we calculated the intraclass correlation coefficients (ICCs) with corresponding 95\% confidence intervals $(\mathrm{Cl})$ between first and second total scores for NPQ and NPQ-SF. An ICC value of $\geq 0.7$ was considered very good, while $>0.8$ was considered excellent (1).

Construct validity was evaluated by interrogating the correlation between NPQ, NPQ-SF, and NRS. Concurrent validity was evaluated by correlating the NPQ, NPQ-SF, DN4, and LANSS. Correlation analysis was performed with Pearson's correlation coefficient given the assumption that the sample pairs are independent and identically distributed and follow a bivariate normal distribution. The relations were interpreted as highly, moderately, and weakly correlated when $r \geq 0.60, r=0.30-0.60$, and $r \leq 0.30$, respectively (1).

\section{RESULTS}

\section{Study Participants}

This study consists of 101 patients with chronic pain (36 men [\%36], 65 women [\%64]; mean age, $50.4 \pm 14.49$ years; mean symptom duration, $63.54 \pm 73.29$ months). Mean NPQ and NPQ-SF scores were $0.02 \pm 1.04$ and $0.0 \pm 1.02$, respectively. Table I shows the demographic and clinical variables.

Table I: Demographic and Clinical Features of Patients Participated in the Study

\begin{tabular}{lcccc}
\hline & $\mathbf{n}$ & $\%$ & Mean \pm SD & Median (Min-Max) \\
\hline Gender & & & \\
\hline \multicolumn{1}{c}{ Male } & 36 & $36 \%$ & \\
\hline \multicolumn{1}{c}{ Female } & 65 & $64 \%$ & & \\
\hline Age (Years) & & & $50.4 \pm 14.49$ & $49-87)$ \\
\hline Symptom duration (months) & & $63.54 \pm 73.29$ & $48(3-300)$ \\
\hline Height (m) & & $1.65 \pm 0.08$ & $1.65(1.48-1.87)$ \\
\hline Weight (kg) & & $77.52 \pm 12.32$ & $77(45-116)$ \\
\hline BMI (kg/m²) & & $28.52 \pm 4.46$ & $27.68(18.73-42.61)$ \\
\hline NPQ total score & & $0.02 \pm 1.04$ & $-0.08(-1.73-3.12)$ \\
\hline NPQ-SF total score & & $0.0 \pm 1.02$ & $-0.11(-1.3-3)$ \\
\hline DN4 score & & $4.38 \pm 2.65$ & $4(0-10)$ \\
\hline LANSS score & & $9.5 \pm 5.54$ & $10(0-23)$ \\
\hline NRS & & $5.58 \pm 2.28$ & $5(2-10)$
\end{tabular}

BMI: Body mass index, NPQ: Neuropathic pain questionnaire, NPQ-SF: Neuropathic pain questionnaire-short form, DN4: Douleur Neuropathique 4, LANSS: Leeds Assessment of Neuropathic Symptoms, NRS: Numeric rating scale. 
Yurdakul OV. et al: Neuropathic Pain Questionnaire

Table II: Test-Retest Reliability of NPQ and NPQ-SF Questionnaires

\begin{tabular}{lccccccc}
\hline & \multicolumn{2}{c}{ Test } & \multicolumn{2}{c}{ Retest } & \multirow{2}{*}{ ICC } & $\mathbf{p}^{*}$ & \%95 CI \\
\cline { 2 - 6 } & Mean \pm SD & Median (Min-Max) & Mean \pm SD & Median (Min-Max) & & \\
\hline NPQ & $0.07 \pm 1.2$ & $-0.21(-2.11-3.12)$ & $0.08 \pm 1.22$ & $-0.16(-2.08-3.06)$ & 0.96 & $<0.001$ & $0.95-0.97$ \\
\hline NPQ-SF & $0.01 \pm 1.11$ & $-0.3(-1.3-3)$ & $0.02 \pm 1.12$ & $-0.33(-1.3-3)$ & 0.97 & $<0.001$ & $0.95-0.97$ \\
\hline
\end{tabular}

p* ICC Test, ICC: intra-class correlation, NPQ: Neuropathic pain questionnaire, NPQ-SF: Neuropathic pain questionnaire-short form, Cl: confidence interval.

Table III: Internal Consistency of NPQ and NPQ-SF Questionnaires

\begin{tabular}{lccc}
\hline NPQ & $\begin{array}{c}\text { Cronbach's } \\
\text { Alpha }\end{array}$ & NPQ-SF & $\begin{array}{c}\text { Cronbach's } \\
\text { Alpha }\end{array}$ \\
\hline S1 & 0.83 & S4 & 0.35 \\
\hline S2 & 0.83 & S6 & 0.47 \\
\hline S3 & 0.82 & S11 & 0.79 \\
\hline S4 & 0.82 & & \\
\hline S5 & 0.83 & & \\
\hline S6 & 0.82 & & \\
\hline S7 & 0.84 & & \\
\hline S8 & 0.84 & & \\
\hline S9 & 0.83 & & \\
\hline S10 & 0.83 & Total \\
\hline S11 & 0.84 & & \\
\hline S12 & 0.84 & & \\
\hline Total & 0.84 & & \\
\hline SPQ: & & & \\
\hline
\end{tabular}

NPQ: Neuropathic pain questionnaire, NPQ-SF: Neuropathic pain questionnaire-short form.

Table IV: Correlations between NPQ, NPQ-SF, DN4, and LANSS

\begin{tabular}{lcc}
\hline & DN4 & LANSS \\
\hline NPQ & $r$ & $r$ \\
\hline NPQ-SF & $0.69^{*}$ & $0.64^{*}$ \\
\hline
\end{tabular}

r: Pearson's Correlation Test $\left({ }^{*} p<0.001\right), N P Q:$ Neuropathic pain questionnaire, NPQ-SF: Neuropathic pain questionnaire-short form, DN4: Douleur Neuropathique 4, LANSS: Leeds Assessment of Neuropathic Symptoms.

\section{Test-Retest Reliability and Internal Consistency}

Test-retest reliability was performed with a subgroup of 41 patients ( 11 males, 30 females; mean age, $47.83 \pm 14.2$ years). The mean NPQ scores for the first and second completions were $0.07 \pm 1.2$ and $0.08 \pm 1.22$, respectively. The mean NPQSF scores were $0.01 \pm 1.11$ and $0.02 \pm 1.12$, respectively. The ICC values for the NPQ and NPQ-SF were $0.96(p<0.001$; $95 \% \mathrm{Cl}, 0.95-0.97)$ and $0.97(\mathrm{p}<0.001 ; 95 \% \mathrm{Cl}, 0.95-0.97)$, respectively, indicating a high reliability (Table II). Internal consistency by Cronbach's-a was 0.84 for NPQ and 0.67 for NPQ-SF, indicating adequate and low internal consistency, respectively (Table III).

\section{Construct and Concurrent Validity}

Total NPQ and NPQ-SF scores were moderately correlated with NRS $(r=0.43$ and 0.45 , respectively; $p<0.001)$. Total NPQ score was highly correlated with DN4 and LANSS scores $(r=0.69$ and 0.64 , respectively; $p<0.001$; Table IV), as was total NPQ-SF score ( $r=0.68$ and 0.60 , respectively; $p<0.001)$.

\section{DISCUSSION}

We translated and culturally adapted NPQ and NPQ-SF, and tested the reliability and validity of these questionnaires. Our results demonstrated the reliability and validity of the Turkish NPQ and NPQ-SF in patients with chronic pain. To our knowledge, our study is the first cross-cultural adaptation and validation of these questionnaires among Turkish-speaking patients with chronic pain.

There are many different causes of nerve damage and the presence or severity of pathology does not correlate with the presence of pain. Since the diagnosis of neuropathic pain is time-consuming and depends on additional testing, development of tools to identify neuropathic pain practically has become a necessity $(2,12)$. From the development of the McGill Pain Questionnaire in the 1970s, it has become apparent that some pain descriptors were more frequent in neuropathic pain, such as burning, pricking, and tugging (8). Boureau et al. found that they could differentiate neuropathic from nonneuropathic pain with $66 \%$ accuracy only by verbal descriptors (8). However, they did not develop a questionnaire. In this manner, the NPQ and NPQ-SF aimed to establish best and most common verbal descriptors to distinguish neuropathic from nonneuropathic pain. In contrast with the DN4 and LANSS pain scales, the NPQ is a self-reported questionnaire and, therefore, does not include sensory examination. Not requiring any examination tool (e.g., brush, needle) may be practical from time to time; however, sometimes it is considered as a disadvantage because it may be hard to diagnose neuropathic pain without examination (13). 
Internal consistency was determined as adequate for the NPQ (Cronbach's- $\mathrm{a}=0.84$ ) and low for NPQ-SF (Cronbach's- $\mathrm{a}=$ $0.67)$. The original 32 -item questionnaire demonstrated a high internal consistency (Cronbach's-a=0.95) (17). However, there is no data for the 12-item and 3-item questionnaires. A study on the Chinese NPQ version demonstrated a Cronbach's-a coefficient of 0.809 , which is similar to our findings. In addition, Terkawi et al. showed a low internal consistency (Cronbach's- $\mathrm{a}=0.45$ ) for the Arabic NPQ-SF version (21), which is consistent with our findings. As internal consistency refers to how well the scale items measure the underlying construct, we may conclude that the final score of NPQ-SF does not indicate the seriousness of neuropathic pain (21).

Test-retest reliability represents the stability of the questionnaire over time with repeated testing. The original NPQ and NPQ-SF versions did not examine test-retest reliability $(3,17)$. Good test-retest reliability was found in the Swedish NPQ version (Cohen's k coefficient $=0.89$ ) (14) and the Arabic NPQ-SF version (ICC=0.78) (21). Our results indicated a high test-retest reliability for the NPQ and NPQ-SF questionnaires (ICC $=0.96$ and 0.97 , respectively, $p<0.001$ ), which demonstrates how consistent and explicit the verbal descriptors are stated by the patients with chronic neuropathic pain.

The total NPQ and NPQ-SF scores showed a moderate correlation with NRS ( $r=0.43$ and 0.45 ; respectively; $p<0.001$ ), thus, indicating a reliable construct validation. In addition, these questionnaires showed a high correlation with DN4 ( $r=$ 0.69 for NPQ and $r=0.68$ for NPQ-SF; $p<0.001)$ and LANSS $(r=0.64$ for $N P Q$ and $r=0.60$ for NPQ-SF; $p<0.001$ ). Except for bedside examination, many common verbal descriptors exist for DN4, LANSS, and NPQ (e.g., pricking, tingling, pins and needles, electric shocks, and shooting pain). In this context, a high correlation between these questionnaires was expected.

\section{CONCLUSION}

We demonstrated the NPQ and NPQ-SF questionnaires to be valid tools for evaluating neuropathic pain in Turkish chronic pain patients. The results indicated adequate and low internal consistency for NPQ and NPQ-SF, respectively. In addition, we demonstrated a high test-retest reliability for these questionnaires. We believe this study will provide physicians a new tool for assessing neuropathic pain among Turkishspeaking patients for clinical and research purposes.

\section{ACKNOWLEDGEMENTS}

We would like to thank Rukiye Buyukgoksel and Hilal Yildiz for their help in conducting the study. Finally, we would like to acknowledge Fatih Usen for analyzing the statistical data.

\section{REFERENCES}

1. Andresen EM: Criteria for assessing the tools of disability outcomes research. Archives of Physical Medicine and Rehabilitation 81:S15-20, 2000
2. Backonja MM, Attal N, Baron R, Bouhassira D, Drangholt M, Dyck PJ, Edwards RR, Freeman R, Gracely R, Haanpaa MH, Hansson P, Hatem SM, Krumova EK, Jensen TS, Maier C, Mick G, Rice AS, Rolke R, Treede RD, Serra J, Toelle T, Tugnoli V, Walk D, Walalce MS, Ware M, Yarnitsky D, Ziegler D: Value of quantitative sensory testing in neurological and pain disorders: NeuPSIG consensus. Pain 154:1807-1819, 2013

3. Backonja MM, Krause SJ: Neuropathic pain questionnaireshort form. Clin J Pain 19:315-316, 2003

4. Beaton DE, Bombardier C, Guillemin F, Ferraz MB: Guidelines for the process of cross-cultural adaptation of self-report measures. Spine 25:3186-3191, 2000

5. Bennett M: The LANSS Pain Scale: The Leeds assessment of neuropathic symptoms and signs. Pain 92:147-157, 2001

6. Bennett MI, Attal N, Backonja MM, Baron R, Bouhassira $D$, Freynhagen R, Scholz J, Tolle TR, Wittchen HU, Jensen TS: Using screening tools to identify neuropathic pain. Pain 127:199-203, 2007

7. Bouhassira D, Attal N, Alchaar H, Boureau F, Brochet B, Bruxelle J, Cunin G, Fermanian J, Ginies P, Grun-Overdyking $A$, Jafari-Schluep $H$, Lanteri-Minet $M$, Laurent B, Mick G, Serrie A, Valade D, Vicaut E: Comparison of pain syndromes associated with nervous or somatic lesions and development of a new neuropathic pain diagnostic questionnaire (DN4). Pain 114:29-36, 2005

8. Boureau F, Doubrere JF, Luu M: Study of verbal description in neuropathic pain. Pain 42:145-152, 1990

9. Eckeli FD, Teixeira RA, Gouvêa ÁL: Neuropathic pain evaluation tools. Revista Dor 17:20-22, 2016

10. Freynhagen R, Baron R, Gockel U, Tolle TR: pain DETECT: A new screening questionnaire to identify neuropathic components in patients with back pain. Curr Med Res Opin 22:1911-1920, 2006

11. Gliem JA, Gliem RR: Calculating, interpreting, and reporting Cronbach's alpha reliability coefficient for Likert-type scales. Midwest Research-to-Practice Conference in Adult, Continuing, and Community Education, 2003 (Refereed Paper)

12. Haanpaa M, Attal N, Backonja M, Baron R, Bennett $M$, Bouhassira D, Cruccu G, Hansson P, Haythornthwaite JA, lannetti GD, Jensen TS, Kauppila T, Nurmikko TJ, Rice AS, Rowbotham M, Serra J, Sommer C, Smith BH, Treede RD: NeuPSIG guidelines on neuropathic pain assessment. Pain 152:14-27, 2011

13. Haanpaa M, Treede RD: Diagnosis and classification of neuropathic pain: Epidemiology and impact of neuropathic pain. Pain Clinical Updates 18(7):1-6, 2010

14. Hallstrom $H$, Norrbrink C: Screening tools for neuropathic pain: Can they be of use in individuals with spinal cord injury? Pain 152:772-779, 2011

15. Harden N, Cohen M: Unmet needs in the management of neuropathic pain. J Pain Symptom Manage 25:S12-17, 2003

16. Jensen M, Karoly P: Self-report scales and procedures for assessing pain in adults. In: Turk D, Melzack R (eds), Handbook of Pain Assessment. New York: The Guilford Press, 2001:15-34 
17. Krause SJ, Backonja MM: Development of a neuropathic pain questionnaire. Clin J Pain 19:306-314, 2003

18. Li J, Feng Y, Han J, Fan B, Wu D, Zhang D, Du D, Li H, Lim J, Wang J, Jin Y, Fu Z: Linguistic adaptation, validation and comparison of 3 routinely used neuropathic pain questionnaires. Pain Physician 15:179-186, 2012

19. Mercadante S, Gebbia V, David F, Aielli F, Verna L, Casuccio A, Porzio G, Mangione S, Ferrera P: Tools for identifying cancer pain of predominantly neuropathic origin and opioid responsiveness in cancer patients. J Pain 10:594-600, 2009

20. Portenoy R: Development and testing of a neuropathic pain screening questionnaire: ID pain. Curr Med Res Opin 22:15551565, 2006

21. Terkawi AS, Backonja MM, Abolkhair A, Almaharbi S, Joy J, Foula F, Alswiti M, Terkawi YS, Al-Zhahrani T, Alghamdi FS, Tsang S: Development and validation of Arabic version of the Neuropathic Pain Questionnaire-short form. Saudi J Anaesth 11:S53-s62, 2017
22. Treede RD, Jensen TS, Campbell JN, Cruccu G, Dostrovsky JO, Griffin JW, Hansson P, Hughes R, Nurmikko T, Serra J: Neuropathic pain: Redefinition and a grading system for clinical and research purposes. Neurology 70:1630-1635, 2008

23. Unal-Cevik I, Sarioglu-Ay S, Evcik D: A comparison of the DN4 and LANSS questionnaires in the assessment of neuropathic pain: validity and reliability of the Turkish version of DN4. J Pain 11:1129-1135, 2010

24. van Hecke O, Austin SK, Khan RA, Smith BH, Torrance N: Neuropathic pain in the general population: A systematic review of epidemiological studies. Pain 155:654-662, 2014

25. Yucel A, Senocak M, Kocasoy Orhan E, Cimen A, Ertas M: Results of the Leeds assessment of neuropathic symptoms and signs pain scale in Turkey: A validation study. J Pain 5:427-432, 2004 